\title{
FACTORS FOR IMPROVING AND MODERATING A SUCCESSFUL SUPPLY CHAIN
}

\author{
Yu Wen $\mathrm{SHI}^{1}$, Ping-Kuo $\mathrm{CHEN}^{2^{*}(\mathrm{D})}$, Yong $\mathrm{YE}^{3^{*}}$ \\ ${ }^{1}$ Department of Information Technology, Wenzhou Vocational \& Technical College, \\ Wenzhou City, China \\ ${ }^{2}$ Department of Logistics Management, Wenzhou Business College, Wenzhou City, China \\ ${ }^{3}$ Department of Management, Wenzhou Medical University, Wenzhou City, China
}

Received 17 April 2018; accepted 14 November 2018

\begin{abstract}
The purpose of this study is to explore whether the ability to adjust and redistribute resources has a positive effect on improving a supply chain's competitive capabilities. In addition, we also verify whether information transparency is an antecedent to improving the ability to adjust and redistribute resources. Finally, this study explores the moderating effects of investment cost controls and absolute dominance on the relationship between information transparency and the ability to adjust and redistribute resources. A partial least squares (PLS) analysis was the main method used in this study. The empirical data were obtained from the International Manufacturing Strategy Survey (IMSS). Regarding the research results, in addition to the relationships among information transparency, resource adjustment and redistribution ability, and supply chain competitive capabilities, our research results demonstrated that overemphasizing investment cost controls and absolute dominance will moderate the relationship between information transparency and resource adjustment and redistribution ability and further lead to weak competitive capabilities.
\end{abstract}

Keywords: supply chain, information transparency, competitive capabilities, innovation, investment cost, dominant.

JEL Classification: D22.

\section{Introduction}

A supply chain is a structure that includes a complete production and the operational process and encompasses the upstream raw materials to downstream product sales (Christopher, 2016). A supply chain is a process established by all of the partner firms, including suppliers, manufacturers, distributors and retailers (Stadtler, 2015). A successful supply chain is a chain in which all partners must understand each other and must have a good relationship to meet all of their missions and objectives (Shieh-Liang, Tran, \& Ha, 2016) and also achieve superior competitive capabilities, such as those related to cost, quality, delivery, and flexibility

^Corresponding author. E-mails: a1104100@ms23.hinet.net; yong_ye@foxmail.com 
(Joshi, Nepal, Rathore, \& Sharma, 2013; Yusuf et al., 2014). In addition, product innovation is also be deemed to be a competitive capability (Wong, C. W., Wong, C. Y., \& Boon-itt, 2013; Vickery, Koufteros, \& Droge, 2013). Thus, a successful supply chain also means the achievement of product innovation capabilities.

To improve a successful supply chain, close integration and coordination are usually deemed to be critical factors (Lii \& Kuo, 2016; Panayides, 2017). However, an increasing number of studies, such as those by Chan, Ngai, and Moon (2017) and Dubey, Gunasekaran, and Childe (2018), have indicated that a good resource adjustment and redistribution ability may be just as important as integration and coordination. Resources usually involve capacity, equipment, humans, and other factors. The ability to adjust and redistribute resources is needed when manufacturers and their partners are handling existing orders but then new orders come in. This ability allows them to immediately analyse and integrate existing available resources and further adjust or redistribute them to address the new orders (Fischl, Scherrer-Rathje, \& Friedli, 2014).

Actually, manufacturers and partners usually have to address continuous orders. Therefore, when they focus on existing orders, a new order may suddenly come in. To satisfy every order, manufacturers and partners cannot postpone the new order and only focus on existing orders. They need to handle existing and new orders immediately and avoid delays. However, each order usually has different demands, and different demands require different internal resources to address them. In addition, since several orders with different demands need to be handled concurrently, it's important to determine how to analyse and immediately integrate available resources and further adjust or redistribute them to address the new orders.

The lack of a good ability to adjust and redistribute resources and having idle resources on hand will increase costs. In this scenario, new orders cannot be handled immediately, service quality will suffer, and delivery of the new orders will be delayed. If the order has specific or customized demands, the ability to be flexible and reactive will be affected. If the new order concerns new product development, manufacturers will also not be able to coordinate the related resources with their partners for product development. Thus, the lack of resource adjustment and redistribution ability also affects the achievement of the supply chain's competitive capabilities.

To improve resource adjustment and redistribution ability, the information used by manufacturers and partners in production and operations should be completely transparent. Information transparency means that related internal resource information, including capacity, human resources, equipment, and others, should be fully released (Shou, Zheng, $\& \mathrm{Zhu}, 2016)$. When all information is released, manufacturers and partners are able to understand the resource usage situation and quickly adjust and redistribute available resource to address a new order.

However, to improve information transparency, partners usually need to invest a large amount of money into information system development to improve information circulation. In addition, some partners concerned with information transparency may release their confidential information, which could lead to an attack from a competitor. Therefore, some partners may not be willing to share their information, which will lead to incomplete information transparency. Based on the above, supply chain leaders usually adopt absolute dominance to push every partner for information transparency. 
However, large investment costs may also lead to hesitancy by partners, and they will be more likely to ask themselves if these investment costs are even necessary (Mohd Yusoff, Ashari, \& Salleh, 2016). If these partners cannot ensure that the investment costs will improve information transparency and lead to greater profit, then they may take a passive attitude and control their investment costs (Abdi \& Labib, 2017). However, to improve information transparency, investment in information systems is necessary, or information transparency improvements will be affected and lead to a low resource adjustment and redistribution ability (Yinan, Tang, \& Zhang, 2014). Based on the above, controlling the cost of investing in information systems may moderate the relationship between information transparency and the ability to adjust and redistribute resources.

In addition, to ensure that every partner is willing to share resource information, it is necessary for the supply chain leader to adopt absolute dominance. However, overemphasizing absolute dominance may lead to dependency by partners (Yuen \& Thai, 2017). This dependency will cause partners to express a passive attitude and only react to the demands of the supply chain leader. Thus, they will decrease their participation in joint resource adjustments and redistribution when they receive a new order (Mandal, 2016). Based on the above, an overemphasis on absolute dominance may also moderate the relationship between information transparency and resource adjustment and redistribution ability. As mentioned earlier, we believe that resource adjustment and redistribution ability is a critical factor in improving successful supply chains and achieving superior competitive capabilities. To improve resource adjustment and redistribution ability, information transparency must be an antecedent. To ensure information transparency, it is necessary to invest in information systems and adopt absolute dominance to guide all partners in sharing complete information. However, if partners overemphasize investment cost control and absolute dominance, they may diminish the relationship between information transparency and resource adjustment and redistribution ability.

Based on the above, we developed a theoretical framework. However, existing studies do not explore this framework, so we cannot ensure that it will be supported. However, if the theoretical framework can be verified, some traditional concepts can be overturned, and the framework can contribute valuable research results to help practitioners establish a successful supply chain for achieving competitive advantage. For this reason, the purpose of this study is to test whether resource adjustment and redistribution ability has positive effects on improving the competitive capability of a supply chain. In addition, we also verify whether information transparency is a precursor to improving the ability to adjust and redistribute resources. Finally, this study further explores the moderating effects of investment cost control and absolute dominance on the relationship between information transparency and resource adjustment and redistribution ability.

\section{Literature review}

In the exploration of establishing a successful supply chain, the existing research usually focuses on the integration issue. According to Teng and Hsu (2017), supply chain integration means "to be combined to form a more complete organization, where each member organization, business process, and information system are linked and synced carefully as if it were a single supply chain job and a well-coordinated system". 
Integration is an important issue in the supply chain research field, and it is an important foundation of supply chain improvements. In establishing integration, manufacturers and partners should first formulate a cooperative-conscious construct (Wang, Childerhouse, Kang, Huo, \& Mathrani, 2016; Liao, Kuo, \& Ding, 2017). Based on the conscious construct, there is a need to further integrate physical and information resource flows (Rodrigues, Dalcol, Pizzolato, \& Maruyama, 2013; Świerczek, 2014). When the physical and information resource flows are integrated, partners can effectively collaborate with regard to any production activity in the supply chain, which will further increase the practical efficiency and satisfy the requirements of businesses' and customers' orders (Soliman, 2015).

Based on above, to establish a successful supply chain, related studies tried to explore how to perform an effective integration. For example, Ralston, Blackhurst, Cantor, and Crum (2015) adopted the perspective of structure-conduct-performance to explore strategic supply chain integration. Aitken, Childerhouse, Deakins, and Towill (2015) explored the improvement of supply chain integration using an uncertainty circle model. In addition, some studies have explored how use information technology to improve supply chain integration (Tseng \& Liao, 2015; Vanpoucke, Vereecke, \& Muylle, 2017).

However, establishing integration among partners is difficult (Mason \& Lalwani, 2006). Hsieh and Hung (2009) noted that the main reason for this difficulty is that different partners may have different, possibly conflicting, objectives. Based on the above, use of the concept of coordination to establish integration has become a hot topic in recent years. Coordination is communication among partners (Mustafa Kamal \& Irani, 2014; Qrunfleh \& Tarafdar, 2014) and can sometimes require a negotiation (Panda, Modak, \& Pradhan, 2015). To effectively coordinate, related studies usually provide valuable suggestions from two perspectives. The first perspective is the development of a coordination mechanism, such as designing information communication technology (Ghobakhloo, Tang, Sabouri, \& Zulkifli, 2014; Liu, Shang, \& Lai, 2015) or management skills (Gao \& Tian, 2014; Masten \& Kim, 2015).

Actually, coordination is suitable for the initial integration because it focuses on establishing integration via the conscious approach. According to related literature, such as that of Liu, Ke, Kee Wei, and Hua (2013) and Mackelprang, Robinson, Bernardes, and Webb (2014), when a conscious construct is established, it leads to an integration of physical and information resource flows and further improves the practice of the supply chain. However, it has increasingly been found that some barriers can exist and affect the integration of physical and information resource flows. Some barriers can be solved through coordination, but some barriers may be difficult to solve through coordination because these barriers are derived from the external environment or the individual partner's internal structure and need to be solved by a specific approach. Therefore, studies have begun to identify and explore these barriers. For example, Awasthi and Grzybowska (2014) defined 17 barriers that affect the establishment of integration, and Byrom, Lawley, and Clements (2016) found barriers that may affect the establishment of physical and information resource integration. Additionally, Lam (2013) indicated that the method of maintaining the partners' relationships is the biggest barrier after coordination.

In addition to integration and coordination, recently, a few studies, such as those by Colurcio, Caridà, and Edvardsson (2017), Chiadamrong and Piyathanavong (2017), found that 
manufacturers and their partners who possess a resource adjustment and redistribution ability may affect the improvement of the supply chain. According to the concept of Fischl et al. (2014), a resource usually involves capacity, equipment, humans, and others. When any order is taken, the manufacturer and its partners need to analyse the order demands and make further plans related to their resources to handle the order. The resource adjustment and redistribution ability means that when manufacturers and their partners are handling existing orders but a new order appears, they can quickly analyse and integrate their existing available resources and further adjust or redistribute resources to address the new order (Fischl et al., 2014). In the past, the resource adjustment and redistribution ability was only seen as one factor for supply chain decision making or planning (Devlin \& Talbot, 2014), and it was not deemed to be a critical factor for improving the supply chain. However, Chen, and Dong (2014), Kwon, Kim, and Martin (2016), Shahi, Pulkki, Leitch, and Gaston (2017) found that if manufacturers and their partners were able to understand their existing available resources at any time and further adjust and redistribute them, this ability may have a positive effect on improving successful supply chains to achieving competitive capabilities.

Nonetheless, existing studies have not verified the importance of the resource adjustment and redistribution ability on the establishment of a successful supply chain. In addition, if the resource adjustment and redistribution ability is actually a critical factor for the establishment of a successful supply chain, how to improve it and determining which factors moderate it still require verification. Based on the above, this study extends existing studies and further explores the influence and importance of the resource adjustment and redistribution ability. In addition, this study also explores which factors improve the resource adjustment and redistribution ability and which factors moderate the resource adjustment and redistribution ability.

\section{Research hypotheses}

In accordance with the research purpose, we develop a theoretical research framework. The theoretical research framework is shown in Figure 1. Based on the framework, 5 hypotheses are developed as follows.

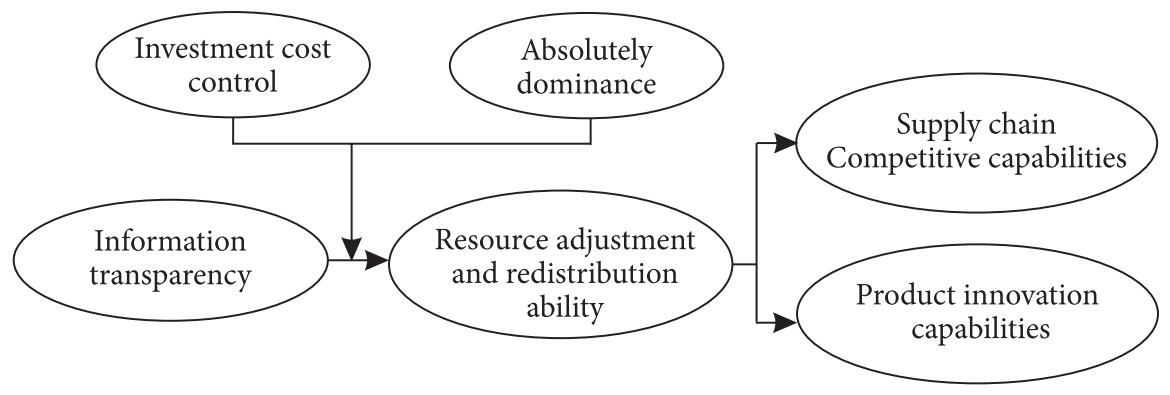

Figure 1. Research theoretical framework 


\subsection{The relationship between information transparency and the resource adjustment and redistribution ability}

Information transparency means that related resource information, including capacity information, such as human, equipment, and others, should be completely released to the supply chain partners (Shou et al., 2016). The resource adjustment and redistribution ability means that when manufacturers and their partners are handling existing orders but new orders appear, they can immediately analyse and integrate their existing available resource, and further adjust or redistribute them to address the new order (Fischl et al., 2014). According to related studies, such as that of Wang, Q., Wang, Y., and Lv (2015), if resource information lacks transparency, the supply chain will lose its flexible responsiveness in regard to resource adjustment and redistribution. Based on the above, the following hypothesis is explored in this study:

H1: Information transparency positively affects the resource adjustment and redistribution ability.

\subsection{The relationships among the resource adjustments and redistribution ability, supply chain competitive capabilities, and product innovation capabilities of a supply chain}

Since the resource adjustment and redistribution ability can quickly analyse and integrate existing available resources and further adjust or redistribute them to address new orders, related studies, such as those of Chen and Dong (2014), Kwon et al. (2016), and Shahi et al. (2017), found that this ability may have a positive effect on improving a supply chain's competitive capabilities and product innovation capabilities. For example, the resource adjustment and redistribution ability can minimize related costs, including production and inventory costs (Habib, Lee, \& Memon, 2016); increase the service and relationship quality with the customer (Huo, Wang, Zhao, \& Schuh, 2016); control for order scheduling and delivery lead-times (Scavarda, Seok, \& Nof, 2017); and maximize order responsiveness (Khayal, Pradhananga, Pokharel, \& Mutlu, 2015; Scavarda et al., 2017). More importantly, Chu, Chiu, and Chi (2015) and Chung, Chao, Lou, and Vinh (2015) indicated that an agile resource adjustment and redistribution ability will improve product innovation. Based on the above, the following hypothesis is verified in this study:

H2a: The resource adjustment and redistribution ability directly affects supply chains' competitive capabilities.

$H 2 b$ : The resource adjustment and redistribution ability directly affects the product innovation capabilities of supply chains.

\subsection{The moderating effect of investment cost control and absolutely dominance}

According to the research purpose, investment cost controls and absolutely dominant leaders are inferred, which may moderate the relationship between information transparency and the resource adjustment and redistribution ability.

Few studies address this question in relation to the moderating effect of investment cost controls. Regarding investment costs, as was stated in section 3.1.1, after the formulation of 
information transparency, partners need to develop an information system for related resource information flows. Zhang, Liu, Zhang, and Bai (2015) indicated that this information system construction is an unavoidable investment cost. However, the cost of information system construction is a large, and most partners will usually be hesitant because they cannot ensure that the investment will have positive effects on resource adjustment and redistribution or even result in large profits. Thus, to avoid investment losses, investment costs are controlled. However, Feng (2011) indicated that investment cost controls will decrease with the resource adjustment and distribution speed. Chen (2015) agreed on this concept and believed that controlling investment costs will break the relationship between information transparency and the resource adjustment and redistribution ability. Based on the above, the following hypothesis is explored in this study:

H3a: The investment cost control has a moderator effect on the relationship between information transparency and the resource adjustment and redistribution ability.

In addition, this study also questions whether absolute dominance moderates the relationship between information transparency and the resource adjustment and redistribution ability. Absolute dominance refers to the leader of the supply chain. We know that the responsibility of the supply chain leader is to keep the supply chain working synchronously and to guide the information flow among partners for improved information transparency. If the supply chain leader adopts an absolutely dominant style to improve the information flow to attain transparency, partners' dependency may increase. Since absolute dominance will reduce partners' participation, Homburg and Bucerius (2005), Mandal (2016) and Frantz (2017) indicated that partners will adopt a passive attitude with regard to joint resource adjustments and redistribution when new orders appear. The partners depend on the leader to make every decision and may only simply follow the commands of the supply chain leader. Thus, resource adjustment and redistribution may be complete. However, more problems will be hidden and affect the achievement of supply chains' competitive capabilities and product innovation capabilities (Zhang, 2016). Based on the above, absolute dominance seems to be a moderator. Thus, the following hypothesis is explored in this study:

$H 3 b$ : Absolute dominance, as a moderator, affects the relationship between information transparency and the resource adjustment and redistribution ability.

\section{Methodology}

\subsection{Data collection, sample characteristics, operationalization and variable constructs}

To verify the research hypotheses, this study utilizes an empirical test. Regarding the empirical test, it is important to collect empirical data from industry. Therefore, we designed a questionnaire based on the research problem, hypotheses, and industry situation, then selected respondents from the industry, and conducted further surveys for collecting empirical data. However, this study is a global study. For efficient collection of global empirical data, in addition to designing a questionnaire with universal application to global firms, we needed to ensure that representative firms from global industries could participate in the survey. 
However, these two requirements were big challenges, and the authors found it difficult to rely on their own resources in this regard. For these reasons, the authors joined the International Manufacturing Strategy Survey (IMSS) for the collection of global empirical data.

The IMSS is an international research network; its purpose is to invite research groups from different economics and jointly establish an international cooperative platform to explore global manufacturing actions, strategies, and supply chains. Based on this purpose, research groups from different economies need to jointly design extensive questionnaires based on real manufacturing industry situations in the areas of manufacturing, strategy, and supply chain operations. When an initial questionnaire design is ready, a pre-test is conducted to ensure the questionnaire's reliability and validity. Afterwards, any research group can use the questionnaire to investigate the economies of the more than 30 representative firms and provide feedback to the IMSS platform.

As of 2018, 29 research groups from 22 economies have joined the IMSS, and 870 respondents have provided feedback (that is, the IMSS has collected 870 data samples). These respondents were from Belgium, Brazil, Canada, China, Denmark, Finland, Germany, Hungary, India, Italy, Japan, Malaysia, Norway, Portugal, Romania, Slovenia, Spain, Sweden, Switzerland, Taiwan, The Netherlands, and the USA. Of course, the authors also contributed 50 responses to the IMSS platform. When data collection is complete, the IMSS removes questionnaires with incomplete answers and further verifies the data's validity. In addition, the IMSS continually updates these data. This means that every research group should cooperate with the IMSS to investigate and collect the latest empirical data. Thus, the IMSS data usually has high level of credibility and reflects real situations in the world today.

However, how can the IMSS data be used to explore our research question? Actually, since the IMSS is just like a database, we only need to select fit data for our research analysis. According to the research framework, exactly six variables were included in this study: information transparency, resource adjustment and redistribution ability, competitive capabilities, product innovation capabilities, investment cost controls, and absolute dominance. The operationalization of the variables in shown in Table 1 . Based on the operationalization, we further selected data from the related IMSS questions as scale items to build the variable constructs (also shown in Table 1). According to the selective scale items, we then accessed corresponding data from the IMSS. However, we found that only 485 respondents finished answering the questions on the six variables. For this reason, although the IMSS has 870 respondents, only data for 485 respondents can be used to further analyse our research problem.

Based on the above, this study will use 485 samples for further analysis. These samples are from different regions: $56.08 \%$ of the respondents were from Europe, 31.96\% from Asia, and $11.96 \%$ from America. The following is a summary of the data characteristics. The industry classifications of the data sample are $31.72 \%$ - manufacturing of fabricated metal products, except machinery and equipment; $11.84 \%$ - manufacturing of computer, electronic and optical products; $15.75 \%$ - manufacturing of electrical equipment; $26.09 \%$ - manufacturing of machinery and equipment not classified elsewhere; 9.54\% - manufacturing of motor vehicles, trailers and semi-trailers; and 5.06\% - manufacturing of other transportation equipment. Regarding the number of employees of the companies in the sample, $44.48 \%$ had 249 or fewer employees; $15.52 \%$ had between $250-499 ; 8.51 \%$ had between $500-749 ; 3.68 \%$ had between 750-999; and $27.82 \%$ had more than 1,000 . 
Table 1. Operationalization and questionnaire constructs

\begin{tabular}{|c|c|c|}
\hline Variables & Scale items & Operationalization \\
\hline $\begin{array}{l}\text { Infor- } \\
\text { mation } \\
\text { transpar- } \\
\text { ency (IT) }\end{array}$ & $\begin{array}{l}\text { I1. Information integration with suppliers/ } \\
\text { customer } \\
\text { I2. Collaborative approaches with suppliers/ } \\
\text { customer } \\
\text { I3. Joint decision with suppliers/customer } \\
\text { I4. System coupling with suppliers/customer } \\
\text { I5. International sourcing/distribution strat- } \\
\text { egy }\end{array}$ & $\begin{array}{l}\text { Related internal resource information, } \\
\text { including capacity, human resources, } \\
\text { equipment, and others, should be com- } \\
\text { pletely released (Shou et al., 2016). }\end{array}$ \\
\hline $\begin{array}{l}\text { Resource } \\
\text { adjust- } \\
\text { ment and } \\
\text { redistribu- } \\
\text { tion abil- } \\
\text { ity (RA) }\end{array}$ & $\begin{array}{l}\text { S1. Product is produced at multiple plants } \\
\text { within the network } \\
\text { S2. Plant serves the whole world/global mar- } \\
\text { ket } \\
\text { S3. Plant covers the full production process } \\
\text { S4. The role of your plant in the network } \\
\text { (product, market and process focus) is revised } \\
\text { and changed flexibly if needed } \\
\text { S5. The product you produce is the same for } \\
\text { all over the world }\end{array}$ & $\begin{array}{l}\text { When manufacturers and their partners } \\
\text { are handling existing orders but a new } \\
\text { order appears, they can quickly analyse } \\
\text { and integrate their existing available re- } \\
\text { sources and further adjust or redistribute } \\
\text { resources to address the new order (Fis- } \\
\text { chl et al., 2014). }\end{array}$ \\
\hline $\begin{array}{l}\text { Supply } \\
\text { chain } \\
\text { Competi- } \\
\text { tive ca- } \\
\text { pabilities } \\
\text { (SC) }\end{array}$ & $\begin{array}{l}\text { C1. Cost } \\
\text { C2. Quality } \\
\text { C3. Delivery } \\
\text { C4. Flexibility }\end{array}$ & $\begin{array}{l}\text { In this paper, supply chain practice re- } \\
\text { sults were considered to drive competi- } \\
\text { tiveness. In general, competitiveness can } \\
\text { be divided into four types: cost, qual- } \\
\text { ity, delivery, and flexibility (Shepherd \& } \\
\text { Günter, 2011). }\end{array}$ \\
\hline $\begin{array}{l}\text { Product } \\
\text { innova- } \\
\text { tion ca- } \\
\text { pabilities } \\
\text { (PI) }\end{array}$ & $\begin{array}{l}\text { P1. Product customization ability } \\
\text { P2. New product introduction ability } \\
\text { P3. New product assistance }\end{array}$ & $\begin{array}{l}\text { Product innovation capability means the } \\
\text { partners can collaborate on R\&D and the } \\
\text { introduction of new products, including } \\
\text { customization or assistance for customers } \\
\text { to design new products as needed (Kyria- } \\
\text { kopoulos, Hughes, \& Hughes, 2016; F. G. } \\
\text { Gilal, Zhang, Rh. G. Gilal, R. G. Gilal, \& } \\
\text { N. G. Gilal, 2017). }\end{array}$ \\
\hline $\begin{array}{l}\text { Invest- } \\
\text { ment cost } \\
\text { control } \\
\text { (IC) }\end{array}$ & $\begin{array}{l}\text { A1. Positively extent procurement, logistics, } \\
\text { supplier/customer development } \\
\text { A2. Positively extent Product improvement, } \\
\text { Introduction of new product or process tech- } \\
\text { nologies } \\
\text { A3. Positively extent Serving as a hub for } \\
\text { product / process knowledge }\end{array}$ & $\begin{array}{l}\text { Investment cost control means partners } \\
\text { attitudes change or respond when fac- } \\
\text { ing investment cost expenditures (Feng, } \\
\text { 2011). }\end{array}$ \\
\hline $\begin{array}{l}\text { Absolutely } \\
\text { domi- } \\
\text { nance } \\
\text { (AD) }\end{array}$ & $\begin{array}{l}\text { IS1. Effort sharing info with upstream (about } \\
\text { sales forecast, production plans, production } \\
\text { progress and stock level) } \\
\text { IS2. Effort improve joint decision with up- } \\
\text { stream (about sales forecast, production plans } \\
\text { and stock level) } \\
\text { IS3. Effort sharing info with downstream } \\
\text { (about sales forecast, production plans, pro- } \\
\text { duction progress and stock level) } \\
\text { IS4. Effort improve joint decision with down- } \\
\text { stream (about sales forecast, production plans } \\
\text { and stock level) }\end{array}$ & $\begin{array}{l}\text { Absolutely dominance concerns the leader } \\
\text { of a supply chain. If the supply chain lead- } \\
\text { er adopts an absolutely dominant style to } \\
\text { improve the coordination of the partners' } \\
\text { integration, the dependency of the part- } \\
\text { ners may increase. Ultimately, this might } \\
\text { affect the partners' efforts regarding the } \\
\text { integration of physical and information } \\
\text { resource flows (Baraniecka, 2013). }\end{array}$ \\
\hline
\end{tabular}




\subsection{Normality}

After data collection, we needed to test the data normality. The mean, standard deviation, skewness, and kurtosis were calculated (see results in Table 2). Four tests were used to determine normality. As indicated by the results in Table 2, all of the constructs met the normality requirement. Overall, data from all samples satisfied the normality requirement.

Table 2. Results of normality

\begin{tabular}{|c|c|c|c|c|c|c|}
\hline Variables & Scale items & Mean & Std. Deviation & Variance & Skewness & Kurtosis \\
\hline \multirow{5}{*}{$\begin{array}{l}\text { Information } \\
\text { transparency } \\
\text { (IT) }\end{array}$} & I1 & 3.14 & 0.88 & 0.781 & -0.113 & -0.129 \\
\hline & $\mathrm{I} 2$ & 3.09 & 0.93 & 0.856 & -0.172 & -0.324 \\
\hline & I3 & 2.95 & 0.95 & 0.904 & -0.050 & -0.519 \\
\hline & I4 & 2.99 & 0.92 & 0.844 & -0.067 & -0.284 \\
\hline & I5 & 3.00 & 1.06 & 1.131 & -0.173 & -0.616 \\
\hline \multirow{5}{*}{$\begin{array}{l}\text { Resource ad- } \\
\text { justment and } \\
\text { redistribution } \\
\text { ability (RA) }\end{array}$} & S1 & 2.95 & 1.40 & 1.952 & -0.067 & -1.291 \\
\hline & S2 & 3.75 & 1.28 & 1.640 & -0.714 & -0.574 \\
\hline & S3 & 3.90 & 1.18 & 1.393 & -0.909 & -0.030 \\
\hline & S4 & 2.97 & 1.24 & 1.528 & -0.189 & -0.969 \\
\hline & S5 & 3.42 & 1.31 & 1.719 & -0.410 & -0.908 \\
\hline \multirow{4}{*}{$\begin{array}{l}\text { Supply chain } \\
\text { Competitive } \\
\text { capabilities } \\
\text { (SC) }\end{array}$} & $\mathrm{C} 1$ & 2.49 & 0.80 & 0.646 & 0.365 & 0.377 \\
\hline & $\mathrm{C} 2$ & 3.03 & 0.74 & 0.552 & 0.267 & -0.322 \\
\hline & $\mathrm{C} 3$ & 2.92 & 0.72 & 0.518 & 0.329 & -0.018 \\
\hline & $\mathrm{C} 4$ & 3.22 & 0.86 & 0.735 & 0.053 & -0.644 \\
\hline \multirow{3}{*}{$\begin{array}{l}\text { Product in- } \\
\text { novation capa- } \\
\text { bilities (PI) }\end{array}$} & P1 & 2.98 & 0.98 & 0.968 & 0.359 & -0.765 \\
\hline & P2 & 3.17 & 0.98 & 0.958 & 0.165 & -0.744 \\
\hline & P3 & 2.86 & 0.87 & 0.749 & 0.544 & -0.272 \\
\hline \multirow{3}{*}{$\begin{array}{l}\text { Investment } \\
\text { cost control } \\
\text { (IC) }\end{array}$} & $\mathrm{A} 1$ & 4.01 & 1.02 & 1.043 & -0.870 & 0.169 \\
\hline & A2 & 3.71 & 1.15 & 1.318 & -0.525 & -0.631 \\
\hline & A3 & 3.53 & 1.14 & 1.303 & -0.488 & -0.448 \\
\hline \multirow{4}{*}{$\begin{array}{l}\text { Absolutely } \\
\text { dominance } \\
\text { (AD) }\end{array}$} & IS1 & 3.55 & 0.96 & 0.930 & -0.262 & -0.213 \\
\hline & IS2 & 3.43 & 1.01 & 1.018 & -0.217 & -0.438 \\
\hline & IS3 & 3.50 & 1.02 & 1.031 & -0.311 & -0.390 \\
\hline & IS4 & 3.34 & 1.07 & 1.151 & -0.186 & -0.500 \\
\hline
\end{tabular}

\subsection{Methods}

In this study, partial least squares (PLS) analysis was the main method used to test the hypotheses. Actually, PLS is deemed to be a better method to analyse path relationships and moderation. In this study, we used SmartPLS 3.0 as an analytical tool.

According to Hair, Hult, Ringle, and Sarstedt (2016), the constructs for validity and reliability are the highest priority when testing the above research hypotheses. However, Hair et al. noted that if the measurement scale is a formative measurement, we just need to use the 
factor loading, composite reliability (CR), and average variance extracted (AVE) to test the validity and reliability of constructs. A formative measurement scale means that scale items of every variable cause the variable and are not interchangeable among themselves - they are formative. The results in Table 1 show that our variable constructs meet the requirement of a formative measurement scale. Therefore, we used the factor loading, composite reliability (CR), and average variance extracted (AVE) to test the validity and reliability of constructs. The CR should exceed 0.7, and the AVE should exceed 0.5 (Hair et al., 2016). Regarding the factor loadings, all loadings from the same factor should exceed 0.5 .

In addition to the factor loading, $\mathrm{CR}$, and AVE, some researchers try to use scale item reliability, internal consistency reliability, and discriminant validity to test the validity and reliability of constructs. However, Hair et al. indicated that those tests are unnecessary. Specifically, these approaches are meaningless for a variable made up of uncorrelated measures.

When the testing of construct validity and reliability has been finished and the test results have been verified as meeting the requirement, the correlation between variables should be tested before PLS analysis. The correlation test results can provide an initial understanding of the relationship between variables. Next, PLS analysis can begin; these results are expected to indicated whether the hypotheses are supported or not. However, we need to measure the model's goodness of fit when PLS analysis is finished. In this study, the standardized root mean square residual (SRMR) was used as the main index of goodness of fit. Why did we use the SRMR? Actually, the SRMR was initially proposed for use in combination with CB-SEM, but it has also been transferred to PLS. According to Henseler, Hubona, and Ray (2016), Andrei, Zait, Vătămănescu, and Pînzaru (2017), SRMR is reported to be an approximate measure of model goodness of fit, which is why it has been widely adopted for this purpose. For this reason, we considered it reasonable to use the SRMR to measure the model's goodness of fit.

\section{Results and discussion}

\subsection{Test results}

All of the test results regarding validity and reliability are shown in Table 3. According to Table 3, we found that all of the factor loadings exceeded 0.5. The majority of the AVEs exceeded 0.5, and the CR exceeded 0.7, but the AVE of resource adjustment and redistribution ability was still lower than 0.5 . However, its CR still satisfied the requirement, so the convergent validity was acceptable.

Table 3. Construct validity and reliability

\begin{tabular}{|c|c|c|c|c|}
\hline \multicolumn{1}{|c|}{ Variables } & Scale items & Factor loading & C.R. & AVE \\
\hline \multirow{3}{*}{$\begin{array}{l}\text { Information trans- } \\
\text { parency (IT) }\end{array}$} & I1 & 0.842 & \multirow{2}{*}{} & \multirow{2}{*}{0.929} \\
\cline { 2 - 3 } & I2 & 0.891 & \multirow{2}{*}{0.723} \\
\cline { 2 - 3 } & I3 & 0.865 & \\
\cline { 2 - 3 } & I4 & 0.851 & \\
\hline
\end{tabular}


End of Table 3

\begin{tabular}{|c|c|c|c|c|}
\hline Variables & Scale items & Factor loading & C.R. & AVE \\
\hline \multirow{5}{*}{$\begin{array}{l}\text { Resource adjust- } \\
\text { ment and redis- } \\
\text { tribution ability } \\
\text { (RA) }\end{array}$} & S1 & 0.507 & \multirow{5}{*}{0.709} & \multirow{5}{*}{0.343} \\
\hline & S2 & 0.755 & & \\
\hline & S3 & 0.661 & & \\
\hline & S4 & 0.563 & & \\
\hline & S5 & 0.543 & & \\
\hline \multirow{4}{*}{$\begin{array}{l}\text { Supply chain } \\
\text { Competitive capa- } \\
\text { bilities (SC) }\end{array}$} & $\mathrm{C} 1$ & 0.551 & \multirow{4}{*}{0.828} & \multirow{4}{*}{0.552} \\
\hline & $\mathrm{C} 2$ & 0.821 & & \\
\hline & $\mathrm{C} 3$ & 0.736 & & \\
\hline & $\mathrm{C} 4$ & 0.831 & & \\
\hline \multirow{3}{*}{$\begin{array}{l}\text { Product innova- } \\
\text { tion capabilities } \\
\text { (PI) }\end{array}$} & P1 & 0.791 & \multirow{3}{*}{0.830} & \multirow{3}{*}{0.620} \\
\hline & $\mathrm{P} 2$ & 0.815 & & \\
\hline & P3 & 0.756 & & \\
\hline \multirow{3}{*}{$\begin{array}{l}\text { Investment cost } \\
\text { control (IC) }\end{array}$} & $\mathrm{A} 1$ & 0.813 & \multirow{3}{*}{0.828} & \multirow{3}{*}{0.616} \\
\hline & $\mathrm{A} 2$ & 0.777 & & \\
\hline & $\mathrm{A} 3$ & 0.764 & & \\
\hline \multirow{4}{*}{$\begin{array}{l}\text { Absolutely domi- } \\
\text { nance (AD) }\end{array}$} & IS1 & 0.852 & \multirow{4}{*}{0.922} & \multirow{4}{*}{0.748} \\
\hline & IS2 & 0.867 & & \\
\hline & IS3 & 0.880 & & \\
\hline & IS4 & 0.860 & & \\
\hline
\end{tabular}

Next, we tested the correlation between variables. The test results shown in Table 4 show that although the coefficients for every person are on the low side, the $p$-value results demonstrate a significant correlation between variables.

Table 4. Correlation analysis

\begin{tabular}{|c|c|c|c|c|c|c|}
\hline & IT & RA & SC & PI & IC & $\mathrm{AD}$ \\
\hline \multicolumn{7}{|l|}{ IT } \\
\hline $\mathrm{RA}$ & $0.216^{\star *}$ & & & & & \\
\hline SC & $0.361^{\star *}$ & $0.127^{\star \star}$ & & & & \\
\hline PI & $0.334^{\star *}$ & $0.164^{* *}$ & $0.657^{\star *}$ & & & \\
\hline IC & $0.149^{* *}$ & $0.160^{* *}$ & $0.090^{*}$ & $0.126^{\star *}$ & & \\
\hline $\mathrm{AD}$ & $0.586^{\star *}$ & $0.147^{\star *}$ & $0.237^{\star *}$ & $0.255^{\star *}$ & $0.209^{\star *}$ & \\
\hline
\end{tabular}

${ }^{* *} p$-value $\leq 0.01,{ }^{*} p$-value $\leq 0.05$.

The following paragraphs discuss our tests of the research model and hypotheses. In addition to the relationships among information transparency, resource adjustment and redistribution ability, supply chain competitive capabilities, and supply chain product innovation capabilities, we also tested the moderating effects of investment cost controls and absolutely dominant leaders. 
First, we considered the moderating effect of investment cost controls to test the research model; the results are presented in Figure 1. As shown in this figure, the path coefficient between information transparency and resource adjustment and redistribution ability is 0.181 , and the $\mathrm{p}$-value is 0.034 , which is higher than 0.01 but lower than 0.05 . Therefore, the result is significant. Additionally, Figure 1 shows the results for the supply chain resource adjustment and redistribution ability, competitive capabilities, and product innovation capabilities. As seen in this figure, the coefficient between the supply chain resource adjustment and redistribution ability and competitive capabilities is 0.160 , and the p-value is 0.026 , which is also lower than 0.05 . Therefore, this result is also significant. The coefficient between resource adjustment and redistribution ability and product innovation capabilities is 0.164 , and the p-value is 0.028 , which is also lower than 0.05. Again, this result is significant. Based on the above, hypotheses $1,2 \mathrm{a}$, and $2 \mathrm{~b}$ seem to be supported. However, we still must test our hypothesis concerning the moderating effect of investment cost controls. The path coefficient of the moderating effect is 0.202 , and the p-value is 0.043 , which is also lower than 0.05 . This means that the result is significant and hypothesis $3 \mathrm{a}$ is supported. Regarding the goodness of fit of the model, the SRMR is 0.077 and is lower than 0.08 . Thus, the model's fit is also accepted.

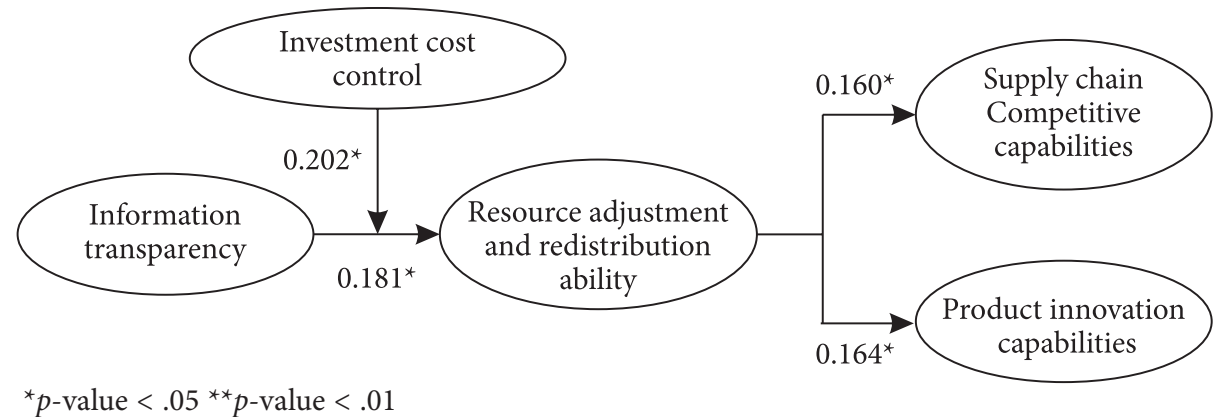

Figure 2. Test results - considering the moderating effect of investment cost control

Next, we considered the moderating effect of absolutely dominant leadership to test the research model. The results are shown in Figure 3, which indicates that the path coefficient between information transparency and resource adjustment and redistribution ability is 0.217 ; the $p$-value is 0.033 , which is lower than 0.05 . Thus, the result is significant. Additionally, the coefficient between the supply chain's resource adjustment and redistribution ability and competitive capabilities is 0.158 , and the $p$-value is 0.026 , which is lower than 0.05 . The coefficient between resource adjustment and redistribution ability and product innovation capabilities is 0.170 , and the $p$-value is 0.030 , which is also lower than 0.05 . This means that the result regarding the relationships among the supply chain's resource adjustment and redistribution ability and competitive and product innovation capabilities are significant. Finally, we examined the moderating effect of absolutely dominant leadership. The path coefficient of the moderating effect is 0.028 , and the $p$-value is 0.001 , which is lower than 0.01 , indicating that the result is significant; thus, hypothesis $3 \mathrm{~b}$ is supported. Regarding the model's fit, the SRMR is 0.070 , which is lower than 0.08 . Thus, the model's fit is also significant. 


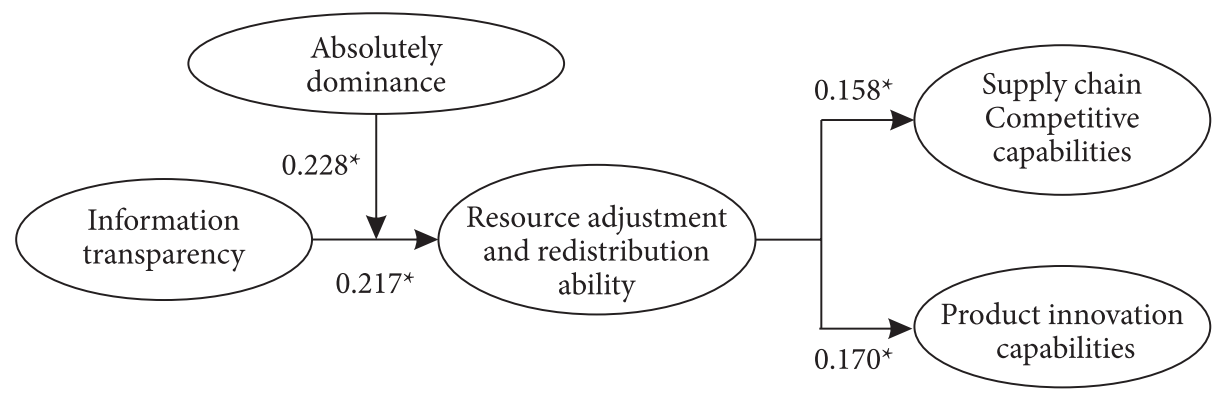

${ }^{*} p$-value $<.05^{* *} p$-value $<.01$

Figure 3. Test results - considering the moderating effect of absolutely dominance

As shown in Figures 2 and 3, in addition to hypotheses 1, 2a, and 2b, a moderating effect of investment cost controls and absolutely dominant leadership is demonstrated. Also shown is the positive effect of information transparency on the ability to adjust and redistribute resources. This ability certainly improves the competitive and product innovation capabilities of supply chains. Finally, investment cost controls and absolutely dominant leadership definitely influence the relationship between information transparency and resource adjustment and redistribution ability.

\subsection{Discussion}

About the relationships among supply chain information transparency, resource adjustment and redistribution ability, competitive capabilities, and product innovation capabilities, based on the test results, we first discuss the relationships among supply chain information transparency, resource adjustment and redistribution ability, competitive capabilities, and product innovation capabilities. Second, we discuss the moderating effect of investment cost controls and absolutely dominant leadership on the relationship between supply chain information transparency and resource adjustment and redistribution ability.

Resource distribution has always been an important issue in the supply chain field. Specifically, every supply chain always needs to handle large orders, and every order has its own demands. Based on these demands, manufacturers and partners usually need to analyse and decide on the resource to be used for addressing these orders. Considering different demands and adjusting and distributing resources are critical factors for satisfying every order. However, orders continue. To maintain a strong customer relationship, manufacturers and partners cannot delay the fulfilment of a new order. In addition, considering the different scheduling and production times, some existing orders may be finished early and appear to be idle resources. Based on the above, if every supply chain possesses resource adjustment and redistribution ability, it can analyse existing orders, integrate idle or available resources, and further use these resources to handle new orders.

When available resources are appropriately used, the supply chain has an advantage and can even improve its own competitive capabilities.

Decrease idle resources and improve a supply chain's competitive capabilities with respect to costs: when related resources are idle, costs will increase. For example, when equipment is 
idle, power is wasted. When workers are idle, human costs will surface. Therefore, if the supply chain can analyse and integrate the available resources, it can improve cost performance.

Increase service quality: when new orders are taken, the order can be handled immediately based on the ability to adjust and redistribute resources. Customers are usually pleased to see that their orders are being handled. Sometimes, when customers discover that their order has been delayed, it may have negative effects on customer relationships. Therefore, a supply chain's competitive capabilities with respect to quality will be improved.

Improve delivery lead-times and avoid order delays: all orders must be handled immediately based on resource adjustment and redistribution ability, which can shorten order lead-times and avoid delays. Therefore, a supply chain's competitive capabilities regarding delivery will be improved.

Increase flexibility to address a specific demand: when specific order demands are met, resource adjustment and redistribution ability can coordinate existing resources and further produce the best resources to handle the demands of the new orders. Therefore, a supply chain's competitive capabilities with respect to flexibility will be improved.

Improve new product innovation capabilities: continuing with the theme of flexibility, when customization or new product demands are met, resource adjustment and redistribution ability can coordinate existing resources and integrate related resources to handle the new order demands with respect to customization or product innovation. Therefore, a supply chain's competitive capabilities with respect to product innovation will be improved.

However, to improve resource adjustment and redistribution ability, information transparency is an important antecedent, and our research results also demonstrated the relationship between information transparency and resource adjustment and redistribution ability. We found that more manufacturers are able to successfully improve their resource adjustment and redistribution ability via information transparency. For example, the Taiwan Semiconductor Manufacturing Company (TSMC), Dell and Samsung require their partners to cooperate with the policy of information transparency to improve their resource redistribution ability. Actually, the concept of resource adjustment and redistribution ability focuses on the analysis and integration of existing available resources. Therefore, if all resource information is not completely transparent, manufacturers and partners have difficulty determining the usage situation of all of their resources and must further adjust and redistribute resources. Based on the above, information transparency is an important antecedent to the improvement of resource adjustment and redistribution ability.

In the moderating effects of investment cost control and absolute dominance, although the relationships among supply chain information transparency, resource adjustment and redistribution ability, and competitive and production innovation capabilities are supported according to our test results, we found that investment cost controls and absolutely dominant leaders moderate the relationship between information transparency and resource adjustment and redistribution ability. Therefore, we further discuss the moderators in this section.

Investment cost controls are usually manifested during the information transparency improvement process. During this process, massive investment costs for information system development are usually required. Actually, effective information transparency depends on improvements brought about by information systems. However, the development of 
information systems involves large expenditures, and partners usually bear the pressure of the investment costs. Because of this pressure, some partners may not agree with ongoing investments if they cannot quickly confirm the results of these investments. Thus, more partners usually opt to control costs when facing this type of investment. However, overemphasizing investment cost controls may decrease the speed of information system development, which will affect improvements in information transparency and further affect the improvement of resource adjustment and redistribution ability. If competitors are quicker to develop information systems, then their resource adjustment and redistribution ability will also increase more quickly. The competitors who do this will have an advantage, considering the relationships among a supply chain's resource adjustment and redistribution ability and competitive and production innovation capabilities. Thus, it is true that partners should not overemphasize investment cost controls during the information transparency improvement process.

In terms of absolutely dominant leaders, although information transparency has a positive effect on improving resource adjustment and redistribution ability and will further improve a supply chain's competitive and product innovation capabilities, more partners worry that information transparency may release too much confidential information and attract attacks by competitors. However, if partners maintain a conservative attitude on information transparency, the improvement of resource adjustment and redistribution ability will be affected. Based on the above, supply chain leaders usually tend to become absolutely dominant. However, when supply chain leaders overemphasize an absolutely dominant style when coordinating with partners for information transparency, these partners usually appear to be dependent.

Although information transparency will be successfully improved through the absolute dominance of the supply chain leader, partners also become increasingly more dependent on the supply chain leader. Finally, although information certainly becomes transparent, partners will become passive when taking new orders and when analysing and integrating available resource for dealing with new order demands. Partners will have a passive attitude towards improving their resource adjustment and redistribution ability, and they will always wait for a command from the supply chain leader. Finally, the supply chain leader will need to be constantly active and will become exhausted. At this point, resource adjustment and redistribution efforts will have difficulty satisfying the demands of new orders, which will result in poor supply chain competitive and product innovation capabilities.

4.3. Contribution, research limitations, and future research

Regarding contributions, our findings extend the literature on supply chains. Actually, the existing literature indicates that integration and coordination are the most critical factors for improving a successful supply chain. Although a few studies have questioned whether resource adjustment and redistribution ability is a new critical factor, this topic has not been addressed much. Researchers such as Lii and Kuo (2016), Zhu, Krikke, and Caniëls, (2018) indicated that greater coordination and integration can improve close partner relationships. This close relationship will heighten the ability of all supply chain partners to respond rapidly to diverse orders. Based on this rapid response capability, they can rapidly improve resource adjustment and redistribution for dealing with different order requirements and further 
achieve the highest level of supply chain competitive and product innovation capabilities. Based on the above, resource adjustment and redistribution cannot have a direct effect on a supply chain's competitive and product innovation capabilities.

However, according to practitioners, while coordination and integration improves a close relationship between partners, to further plan resource adjustments and redistributions, the supply chain partners are still needed. Even when coordination and integration are perfect, if the supply chain partners lack the ability to plan resource adjustments and redistributions, it will be impossible to ensure that the resource can be perfectly adjusted and redistributed to deal with diverse order requirements. For this reason, the ability to adjust and redistribute resources should be discussed on its own. Based on the above, according to our research results, we found that the ability to adjust and redistribute resources has a positive effect on a supply chain's competitive and product innovation capabilities. This means that resource adjustment and redistribution ability certainly is a critical factor for improving the supply chain and achieving highly competitive capabilities as well as product innovation capabilities. Based on the above, our research findings demand that resource adjustment and redistribution ability should be focused on and further discussed. In addition, we also contend that resource adjustment and redistribution ability cannot be augmented along with the improvement of coordination and integration. As such, this study almost raises a new issue and is a significant academic contribution.

In addition to highlighting the importance of resource adjustment and redistribution ability, this study also explored whether information transparency can effectively improve resource adjustment and redistribution ability. Most importantly, this study further explores whether investment cost controls and absolutely dominance can moderate the relationship between information transparency and the ability to adjust and redistribute resources. From this, a comprehensive discussion on resource adjustment and redistribution ability is presented. The discussion results led to the proposal of a theory and contributed to the supply chain research field.

Although our study provides valuable research results and extends the existing supply chain literature, it still has some research limitations. First, although we demonstrated that resource adjustment and redistribution ability is a critical factor for improving successful supply chains and achieving higher competitive and product innovation capabilities, how to analyse and integrate available resources and then effectively adjust and distribute them requires new, serious methods. However, this study does not discuss these methods. In addition, according to the test results, we found that absolute dominance as a moderator affects the relationship between information transparency and resource adjustment and redistribution ability. However, if dominance is reduced, the partners are also likely to lower their intentions regarding information transparency. Therefore, the supply chain leader may need to plan an appropriate leadership style and guide partners towards sharing resource information and further improving information transparency. However, this study also lacks a discussion of the planning required for this appropriate leadership style.

Based on the research limitations, the following lines of research can be further explored in the future. First, develop a method using algorithms or simulations, and use the method to integrate, analyse, adjust and redistribute available resources; second, explore an appropriate 
leadership style to understand which style can be adopted and implemented in the supply chain, and help the supply chain leader guide partners towards information transparency.

\section{Conclusions}

The purpose of this study was to explore whether resource adjusting and redistribution ability has a positive effect on improving a supply chain's competitive and product innovation capabilities. In addition, we also verified whether information transparency is an antecedent to the improvement of resource adjustment and redistribution ability. This study also explored the moderating effects of investment cost controls and absolute dominance on the relationship between information transparency and resource adjustment and redistribution ability. According to the test results, in addition to the relationships among information transparency, resource adjustment and redistribution ability, and four supply chain competitive and product innovation capabilities, we also demonstrated that an overemphasis on investment cost controls and absolute dominance will moderate the relationship between information transparency and resource adjustment and redistribution ability. Lastly, the four competitive and product innovation capabilities are also affected.

Regarding the practical implications of this work, our research results provide a number of suggestions. First, in addition to integration and coordination, manufacturers and partners in the real world should focus on improving their resource adjustment and redistribution ability. Today's competitive environment is one of hyper-competition. If a competitor's resource adjustment and redistribution ability is clearly higher, they will be able to attract and handle more orders and, therefore, capture larger market shares. As such, manufacturers and partners in the real world should positively improve their resource adjustment and redistribution ability.

Second, information transparency is an important antecedent for improving the ability to adjust and redistribute resources. However, improving information transparency usually requires information system development efforts as well as large investment costs. However, these large expenditures usually lead to pressure for partners, who might decide to control these investment costs because of this pressure. However, if the investment costs are diminished, information transparency will be affected. Finally, improving information transparency also affects the improvement of resource adjustment and redistribution ability and leads to poor supply chain competitive and production innovation capabilities. Based on the above, investment costs for information system development are necessary, and manufacturers and partners in the real world should not overemphasize these investment costs.

Third, partners must address the privacy protection of confidential information that could be released during the process of improving information transparency. Because of this concern, partners may adopt a passive attitude towards information transparency. At this point, the supply chain leader usually adopts a position of absolute dominance to improve information sharing between partners. However, the supply chain leader should avoid overemphasizing information sharing, or the partners will become dependent, and improvements in resource adjustment and redistribution ability will be affected.

Based on the research results, this study highlighted the importance of resource adjustment 
and redistribution ability and also revealed a new issue in the supply chain research field. In addition, this study also explored whether information transparency can improve resource adjustment and redistribution ability and whether investment cost controls and absolute dominance can moderate the relationship between information transparency and resource adjustment and redistribution ability. From this, the study also developed a theory to expand the research horizon in the supply chain field. As such, our study provides a significant academic contribution.

Although our research results put forward a research theory based on the importance of resource adjustment and redistribution ability, this study still lacks an exploration of how to develop a method to improve the ability to analyse and integrate available resources and then effectively adjust and distribute resources. In addition, if absolute dominance can affect the relationship between information transparency and resource adjustment and redistribution ability, it also alludes to the leadership issue. However, this study did not explore and discuss the leadership issue. These two limitations of our study may indicate some future research directions. First, we may try to develop a method using algorithms or simulations for the purpose of integrating, analysing, adjusting, and redistributing available resources. Then, we may try to explore or identify an appropriate leadership style to improve the ability to adjust and redistribute resources.

\section{Funding}

This work was supported by the National Natural Science Foundation of China (NSFC) under Grant 71872131 and 71601146.

\section{Author contributions}

Ping-Kuo CHEN and Yong YE conceived the study and were responsible for the design and development of the research concept. YuWen SHI, Ping-Kuo CHEN and Yong YE were responsible for data collection and analysis. YuWen SHI and Ping-Kuo CHEN were responsible for data interpretation. Ping-Kuo CHEN and Yong YE wrote the first draft of the article.

\section{Disclosure statement}

The authors have no competing financial, professional, or personal interests from other parties that are related to the subject of this paper.

\section{References}

Abdi, M. R., \& Labib, A. (2017). RMS capacity utilisation: product family and supply chain. International Journal of Production Research, 55(7), 1930-1956. https://doi.org/10.1080/00207543.2016.1229066

Aitken, J., Childerhouse, P., Deakins, E., \& Towill, D. (2015). A Comparative study of manufacturing and service sector supply chain integration via the uncertainty circle model. The International Journal of Logistics Management, 70(4), 246-258. https://doi.org/10.1108/IJLM-03-2014-0047 
Andrei, A. G., Zait, A., Vătămănescu, E. M., \& Pînzaru, F. (2017). Word-of-mouth generation and brand communication strategy: Findings from an experimental study explored with PLS-SEM. Industrial Management \& Data Systems, 117(3), 478-495. https://doi.org/10.1108/IMDS-11-2015-0487

Awasthi, A., \& Grzybowska, K. (2014). Barriers of the supply chain integration process. In Logistics Operations, Supply Chain Management and Sustainability (pp. 15-30). New York: Springer International Publishing.

Baraniecka, A. (2013). Supply chain development process. In Managing Towards Supply Chain Maturity (pp. 45-86). UK: Palgrave Macmillan.

Byrom, D., Lawley, M., \& Clements, M. (2016). Barriers to supply chain integration in the Australian seafood industry. A Stakeholder Approach to Managing Food: Local, National, and Global Issues, 4, 186-199.

Chan, A. T., Ngai, E. W., \& Moon, K. K. (2017). The effects of strategic and manufacturing flexibilities and supply chain agility on firm performance in the fashion industry. European Journal of Operational Research, 259(2), 486-499. https://doi.org/10.1016/j.ejor.2016.11.006

Chen, J., \& Dong, M. (2014). Available-to-promise-based flexible order allocation in ATO supply chains. International Journal of Production Research, 52(22), 6717-6738. https://doi.org/10.1080/00207543.2014.911419

Chen, P. K. (2015). Impacts of investment attitude in service innovation. Total Quality Management \& Business Excellence, 26(7-8), 875-887. https://doi.org/10.1080/14783363.2014.901802

Chiadamrong, N., \& Piyathanavong, V. (2017). Optimal design of supply chain network under uncertainty environment using hybrid analytical and simulation modeling approach. Journal of Industrial Engineering International, 13(4), 465-478. https://doi.org/ 10.1007/s40092-017-0201-2

Christopher, M. (2016). Logistics \& supply chain management. UK: Pearson.

Chu, L. S., Chiu, W. H., \& Chi, H. R. (2015, June). Exploring market orientation and service innovation strategy of manufacturing industry: A case study of PCC in Taiwan. In Service Systems and Service Management (ICSSSM), 2015 12th International Conference on (pp. 1-6). IEEE.

Chung, C. C., Chao, L. C., Lou, S. J., \& Vinh, N. Q. (2015). Benchmarking-based analytic network process model for strategic management. Journal of Information Hiding and Multimedia Signal Processing, 6(1), 59-73. https://doi.org/ JIH-MSP-2015-01-004

Colurcio, M., Caridà, A., \& Edvardsson, B. (2017). Conceptualizing resource integration to advance service innovation. In Innovating in Practice (pp. 237-259). Switzerland, Cham: Springer.

Devlin, G., \& Talbot, B. (2014). Deriving cooperative biomass resource transport supply strategies in meeting co-firing energy regulations: A case for peat and wood fibre in Ireland. Applied Energy, 113, 1700-1709. https://doi.org/10.1016/j.apenergy.2013.09.019

Dubey, R., Gunasekaran, A., \& Childe, S. J. (2018). Big data analytics capability in supply chain agility: The moderating effect of organizational flexibility. Management Decision (in press). https://doi.org/10.1108/MD-01-2018-0119

Fischl, M., Scherrer-Rathje, M., \& Friedli, T. (2014). Digging deeper into supply risk: a systematic literature review on price risks. Supply Chain Management: An International Journal, 19(5/6), 480-503. https://doi.org/10.1108/SCM-12-2013-0474

Frantz, T. L. (2017). Dissecting Post-Merger Integration Risk: The PMI Risk Framework. In Advances in Mergers and Acquisitions (pp. 133-164). Emerald Publishing Limited. https://doi.org/ 10.1108/S1479-361X20170000016008

Gao, T., \& Tian, Y. (2014). Mechanism of supply chain coordination based on dynamic capability framework-the mediating role of manufacturing capabilities. Journal of Industrial Engineering and Management, 7(5), 1250. https://doi.org/10.3926/jiem.1266

Ghobakhloo, M., Tang, S. H., Sabouri, M. S., \& Zulkifli, N. (2014). The Impact of information systemenabled supply chain process integration on business performance: A Resource-based analysis. In- 
ternational Journal of Information Technology \& Decision Making, 13(05), 1075-1113.

https://doi.org/10.1142/S0219622014500163

Gilal, F. G., Zhang, J., Gilal, Rh. G., Gilal, R. G., \& Gilal, N. G. (2017). Supply chain management practices and product development: a moderated mediation model of supply chain responsiveness, organization structure, and research and development. Journal of Advanced Manufacturing Systems, 16(01), 35-56. https://doi.org/10.1142/S0219686717500032

Habib, M. S., Lee, Y. H., \& Memon, M. S. (2016). Mathematical models in humanitarian supply chain management: A systematic literature review. Mathematical Problems in Engineering, 2016. https://doi.org/10.1155/2016/3212095

Hair J. F., Hult, G. T. M., Ringle, C., \& Sarstedt, M. (2016). A primer on partial least squares structural equation modeling (PLS-SEM). London: Sage Publications.

Henseler, J., Hubona, G., \& Ray, P. A. (2016), Using PLS path modeling in new technology research: updated guidelines. Industrial Management \& Data Systems, 116(1), 2-20.

https://doi.org/10.1108/IMDS-09-2015-0382

Homburg, C., \& Bucerius, M. (2005). A marketing perspective on mergers and acquisitions: How marketing integration affects postmerger performance. Journal of Marketing, 69(1), 95-113. https://doi.org/10.1509/jmkg.69.1.95.55510

Hsieh, C. S., \& Hung, J. W. (2009). Integration agent negotiation and data global consistency forms automatic and none Bullwhip effect supply chain. WSEAS Transactions on Information Science and Applications, 6(6), 1037-1050.

Huo, B., Wang, Q., Zhao, X., \& Schuh, S. (2016). Threats and benefits of power discrepancies between organisations: a supply chain perspective. International Journal of Production Research, 54(13), 3870-3884. https://doi.org/10.1080/00207543.2016.1159744

Joshi, D., Nepal, B., Rathore, A. P. S. \& Sharma, D. (2013). On supply chain competitiveness of Indian automotive component manufacturing industry. International Journal of Production Economics, 143(1), 151-161. https://doi.org/10.1016/j.ijpe.2012.12.023

Khayal, D., Pradhananga, R., Pokharel, S., \& Mutlu, F. (2015). A model for planning locations of temporary distribution facilities for emergency response. Socio-Economic Planning Sciences, 52, 22-30. https://doi.org/10.1016/j.seps.2015.09.002

Kwon, I. W. G., Kim, S. H., \& Martin, D. G. (2016). Healthcare supply chain management; strategic areas for quality and financial improvement. Technological Forecasting and Social Change, 113, 422428. https://doi.org/10.1016/j.techfore.2016.07.014

Kyriakopoulos, K., Hughes, M., \& Hughes, P. (2016). The role of marketing resources in radical innovation activity: antecedents and payoffs. Journal of Product Innovation Management, 33(4), 398-417. https://doi.org/10.1111/jpim.12285

Lam, J. S. L. (2013). Benefits and barriers of supply chain integration: Empirical analysis of liner shipping. International Journal of Shipping and Transport Logistics, 5(1), 13-30. https://doi.org/10.1504/IJSTL.2013.050553

Liao, S. H., Kuo, F. I., \& Ding, L. W. (2017). Assessing the influence of supply chain collaboration value innovation, supply chain capability and competitive advantage in Taiwan's networking communication industry. International Journal of Production Economics, 191, 143-153. https://doi.org/10.1016/j.ijpe.2017.06.001

Lii, P., \& Kuo, F. I. (2016). Innovation-oriented supply chain integration for combined competitiveness and firm performance. International Journal of Production Economics, 174, 142-155. https://doi.org/10.1016/j.ijpe.2016.01.018

Liu, H., Ke, W., Kee Wei, K., \& Hua, Z. (2013). Effects of supply chain integration and market orientation on firm performance: Evidence from China. International Journal of Operations \& Production Management, 33(3), 322-346. https://doi.org/10.1108/01443571311300809 
Liu, Z., Shang, J., \& Lai, M. (2015). Incentive mechanism for knowledge sharing in e-commerce service supply chain: complementarity, integration and risk attitude. Journal of Electronic Commerce Research, 16(3), 175-193. http://www.jecr.org/sites/default/files/16_3_p02.pdf

Mackelprang, A. W., Robinson, J. L., Bernardes, E., \& Webb, G. S. (2014). The relationship between strategic supply chain integration and performance: a meta-analytic evaluation and implications for supply chain management research. Journal of Business Logistics, 35(1), 71-96. https://doi.org/10.1111/jbl.12023

Mandal, S. (2016). Towards an integrated logistics capabilities model of supply chain flexibility: A social exchange perspective. Romanian Economic and Business Review, 11(3), 44-67. Retrieved from http://www.rebe.rau.ro/RePEc/rau/journl/FA16/REBE-FA16-A4.pdf

Mason, R., \& Lalwani, C. (2006). Transport integration tools for supply chain management. International Journal of Logistics: Research and Applications, 9(1), 57-74.

https://doi.org/10.1080/13675560500534599

Masten, K. A., \& Kim, S. L. (2015). So many mechanisms, so little action: The case for 3rd party supply chain coordination. International Journal of Production Economics, 168, 13-20. https://doi.org/10.1016/j.ijpe.2015.06.005

Mohd Yusoff, Y., Ashari, H., \& Salleh, M. N. (2016). The Impact of supply chain management as mediator between strategic orientations and supply chain performance. International Journal of Supply Chain Management, 5(2), 101-107. Retrieved from https://ojs.excelingtech.co.uk/index.php/IJSCM/ article/download/1199/pdf

Mustafa Kamal, M., \& Irani, Z. (2014). Analysing supply chain integration through a systematic literature review: a normative perspective. Supply Chain Management: An International Journal, 19(5/6), 523-557. https://doi.org/10.1108/SCM-12-2013-0491

Panayides, P. M. (2017). Global supply chain integration and competitiveness of port terminals. In Ports, cities, and global supply chains (pp. 43-56). Routledge.

Panda, S., Modak, N. M., \& Pradhan, D. (2016). Corporate social responsibility, channel coordination and profit division in a two-echelon supply chain. International Journal of Management Science and Engineering Management, 11(1), 22-33. https://doi.org/10.1080/17509653.2014.968815

Qrunfleh, S., \& Tarafdar, M. (2014). Supply chain information systems strategy: Impacts on supply chain performance and firm performance. International Journal of Production Economics, 147, 340350. https://doi.org/10.1016/j.ijpe.2012.09.018

Ralston, P. M., Blackhurst, J., Cantor, D. E., \& Crum, M. R. (2015). A structure-conduct-performance perspective of how strategic supply chain integration affects firm performance. Journal of Supply Chain Management, 51(2), 47-64. https://doi.org/10.1111/jscm.12064

Rodrigues, E. F., Dalcol, P. R. T., Pizzolato, N. D., \& Maruyama, Ú. (2013). Virtual organisation model: the new organisation and value chain framework. International Journal of Environmental Technology and Management, 16(5-6), 437-450. https://doi.org/10.1504/IJETM.2013.059445

Scavarda, M., Seok, H., \& Nof, S. Y. (2017). The constrained-collaboration algorithm for intelligent resource distribution in supply networks. Computers \& Industrial Engineering, 113, 803-818. https://doi.org/10.1016/j.cie.2017.05.015

Shahi, S., Pulkki, R., Leitch, M., \& Gaston, C. (2017). Integrating operational planning decisions throughout the forest products industry supply chain under supply and demand uncertainty. International Journal of Forest Engineering, 29(1), 1-11. https://doi.org/10.1080/14942119.2017.1371544

Shepherd, C., \& Günter, H. (2011). Measuring supply chain performance: current research and future directions. In Behavioral Operations in Planning and Scheduling (pp. 105-121). Berlin Heidelberg: Springer.

Shieh-Liang, C., Tran, N. T. H., \& Ha, N. T. T. (2016). Concerns of Vietnamese producing-exporting seafood SMEs (VPESSMEs) on supply chain. International Business Research, 9(6), 120-130. https://doi.org/10.5539/ibr.v9n6p120 
Shou, Z., Zheng, X. V., \& Zhu, W. (2016). Contract ineffectiveness in emerging markets: An institutional theory perspective. Journal of Operations Management, 46, 38-54.

https://doi.org/10.1016/j.jom.2016.07.004

Soliman, F. (2015). Does the cloud system drive supply chain Sustainability?. In Cloud Systems in Supply Chains (pp. 224-245). UK: Palgrave Macmillan.

Stadtler H. (2015). Supply Chain Management: An Overview. In: H. Stadtler, C. Kilger, H. Meyr (Eds) Supply Chain Management and Advanced Planning. Springer Texts in Business and Economics. Berlin, Heidelberg: Springer.

Świerczek, A. (2014). The impact of supply chain integration on the "snowball effect in the transmission of disruptions: An empirical evaluation of the model. International Journal of Production Economics, 157, 89-104. https://doi.org/10.1016/j.ijpe.2013.08.010

Teng, H. M., \& Hsu, P. H. (2017). Optimal ordering decision by increasing the intermediary of supply chain. Asia Pacific Management Review, 22(3), 122-127. https://doi.org/10.1016/j.apmrv.2016.11.001

Tseng, P. H., \& Liao, C. H. (2015). Supply chain integration, information technology, market orientation and firm performance in container shipping firms. The International Journal of Logistics Management, 26(1), 82-106. https://doi.org/10.1108/IJLM-09-2012-0088

Vanpoucke, E., Vereecke, A., \& Muylle, S. (2017). Leveraging the impact of supply chain integration through information technology. International Journal of Operations \& Production Management, 37(4), 510-530. https://doi.org/10.1108/IJOPM-07-2015-0441

Vickery, S. K., Koufteros, X., \& Droge, C. (2013). Does product platform strategy mediate the effects of supply chain integration on performance? A dynamic capabilities perspective. IEEE Transactions on Engineering Management, 60(4), 750-762. https://doi.org/10.1109/TEM.2013.2266301

Wang, B., Childerhouse, P., Kang, Y., Huo, B., \& Mathrani, S. (2016). Enablers of supply chain integration: interpersonal and interorganizational relationship perspectives. Industrial Management \& Data Systems, 116(4), 838-855. https://doi.org/10.1108/IMDS-09-2015-0403

Wang, Q., Wang, Y., \& Lv, F. (2015). Improvement of ecta mode based on the petri network system. In LISS 2013 (pp. 37-48). Berlin, Heidelberg: Springer.

Wong, C. W., Wong, C. Y., \& Boon-itt, S. (2013). The combined effects of internal and external supply chain integration on product innovation. International Journal of Production Economics, 146(2), 566-574. https://doi.org/10.1016/j.ijpe.2013.08.004

Yinan, Q., Tang, M., \& Zhang, M. (2014). Mass customization in flat organization: The mediating role of supply chain planning and corporation coordination. Journal of Applied Research and Technology, 12(2), 171-181. https://doi.org/10.1016/S1665-6423(14)72333-8

Yuen, K. F., \& Thai, V. (2017). Barriers to supply chain integration in the maritime logistics industry. Maritime Economics \& Logistics, 19(3), 551-572. https://doi.org/10.1057/mel.2016.10

Yusuf, Y. Y., Gunasekaran, A., Musa, A., Dauda, M., El-Berishy, N. M. \& Cang, S. (2014). A relational study of supply chain agility, competitiveness and business performance in the oil and gas industry. International Journal of Production Economics, 147, 531-543.

https://doi.org/10.1016/j.ijpe.2012.10.009

Zhang, J., Liu, G., Zhang, Q., \& Bai, Z. (2015). Coordinating a supply chain for deteriorating items with a revenue sharing and cooperative investment contract. Omega, 56, 37-49. https://doi.org/10.1016/j.omega.2015.03.004

Zhang, X. (2016). Research on formation mechanism and intervention mechanism of food cold chain logistics chain destruction. Revista de la Facultad de Ingeniería, 31(7), 121-130. https://doi.org/10.21311/002.31.7.12

Zhu, Q., Krikke, H., \& Caniëls, M. C. (2018). Supply chain integration: value creation through managing inter-organizational learning. International Journal of Operations \& Production Management, 38(1), 211-229. https://doi.org/10.1108/IJOPM-06-2015-0372 